\title{
Correction to: Soliton and shocks in pair ion plasma in presence of superthermal electron
}

\author{
Utpal Kumar Samanta ${ }^{1,2} \cdot$ Prasanta Chatterjee ${ }^{2} \cdot{\text { Monimala } \mathrm{Nej}^{2}}^{2}$
}

Published online: 17 May 2018

(c) Springer Science+Business Media B.V., part of Springer Nature 2018

Correction to: Astrophys Space Sci (2013) 345:291-296

https://doi.org/10.1007/s10509-013-1403-8

There were typos in the last author's name in the original publication. The name is correctly shown here.

The online version of the original article can be found under https://doi.org/10.1007/s10509-013-1403-8.

$凶$ U.K. Samanta

utpalsamanta5@gmail.com

1 Department of Mathematics, Bankura Christian College, Bankura 722101, India

2 Department of Mathematics, Visva Bharati University, Santinekatan 731235, India 